\title{
Endosonography of a Pulmonary Artery Obstruction in Echinococcosis
}

\author{
Mark J. Schuuring ${ }^{a}$ d Peter I. Bonta $^{b}$ Michele van Vugt ${ }^{a}$ Frank Smithuis $^{c}$ \\ Otto M. van Delden ${ }^{c}$ Jouke T. Annema ${ }^{b}$ Kees Stijnis ${ }^{a}$ \\ Departments of ${ }^{\mathrm{a}}$ Internal Medicine, ${ }^{\mathrm{b}}$ Pulmonology, and ${ }^{\mathrm{C}}$ Radiology, Academic Medical Center, Amsterdam, and \\ dDepartment of Cardiology, Haga Teaching Hospital, The Hague, The Netherlands
}

\section{Established Facts}

- A minority of echinococcosis cases involves multiple sites, and cysts in the pulmonary artery (PA) are very rare.

\section{Novel Insights}

- Echinococcosis may cause severe PA obstruction with sudden thoracic pain and shortness of breath.

- In case of uncertainty of the diagnosis at noninvasive imaging, subsequent minimally invasive endobronchial ultrasound is an excellent diagnostic technique to visualize intra-PA cysts and differentiate it from pulmonary embolism.

\section{Key Words}

Pulmonary artery obstruction · Endobronchial ultrasound · Echinococcosis $\cdot$ Hydatidosis · Pulmonary embolism

\begin{abstract}
A 44-year-old woman with a history of pulmonary embolism and abdominal echinococcosis complained of sudden thoracic pain and shortness of breath. A D-dimer of $77.5 \mathrm{mg} / \mathrm{l}$ (reference $\leq 0.5 \mathrm{mg} / \mathrm{l}$ ) was found. Chest CT scan revealed obstruction of the right lower and middle lobe pulmonary artery (PA). Anticoagulation therapy was initiated for the presumed diagnosis of recurrent pulmonary embolism. However, due to persistent symptoms of dyspnea, follow-up CT
\end{abstract}

\section{KARGER}

E-Mail karger@karger.com www.karger.com/res

\section{(C) 2016 The Author(s) \\ Published by S. Karger AG, Basel 0025-7931/16/0926-0425\$39.50/0}

This article is licensed under the Creative Commons AttributionNonCommercial-NoDerivatives 4.0 International License (CC BY NC-ND) (http://www.karger.com/Services/OpenAccessLicense) Usage and distribution for commercial purposes as well as any distribution of modified material requires written permission. angiography of the chest was performed 3 months later. A persistent PA obstruction was found and the presumed diagnosis of embolism was questioned. Subsequently, endobronchial ultrasound (EBUS) imaging was performed to support an alternative diagnosis. EBUS imaging showed an inhomogeneous, sharply demarcated, intravascular lesion with round hypoechoic areas compatible with cysts. The diagnosis of embolism was rejected and treatment with albendazole was initiated for pulmonary echinococcosis. Echinococcosis is a parasitic disease and cystic spread in the PA is exceptional. The patient has remained stable for more than 4 years. In case of disease progression, including progressive PA obstruction or life-threatening hemoptysis, surgical resection will be considered.

(c) 2016 The Author(s)

Published by S. Karger AG, Basel

Dr. Mark J. Schuuring

Department of Internal Medicine

Academic Medical Center

Amsterdam (The Netherlands)

E-Mail m.j.schuuring@ amc.uva.nl 


\section{Introduction}

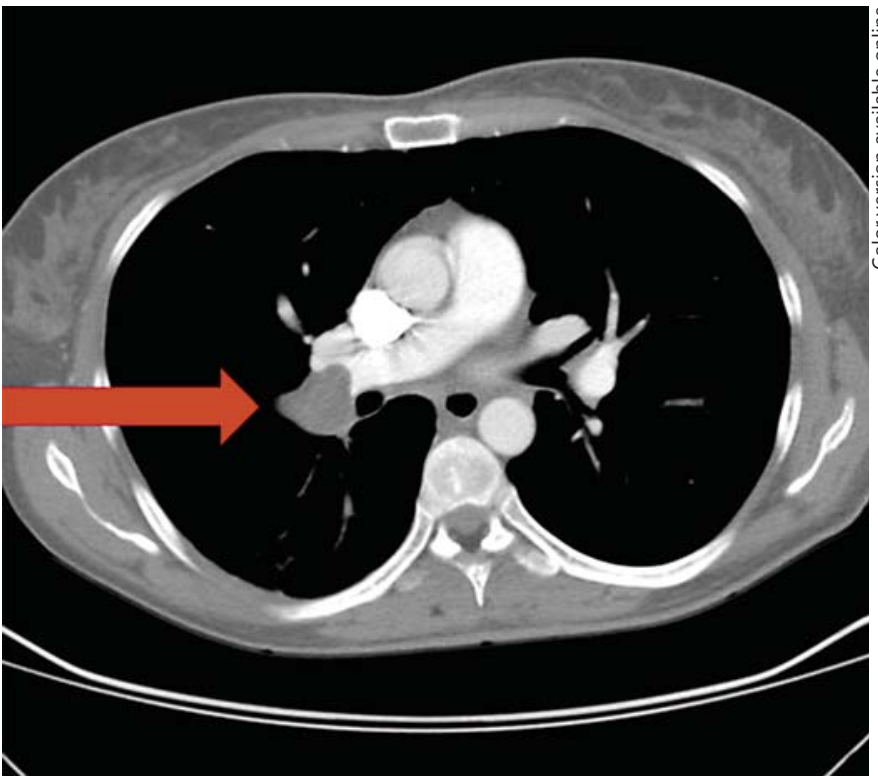

Fig. 1. CT angiography. Axial view showing a right PA thrombus involving the right lower and middle lobe (arrow).

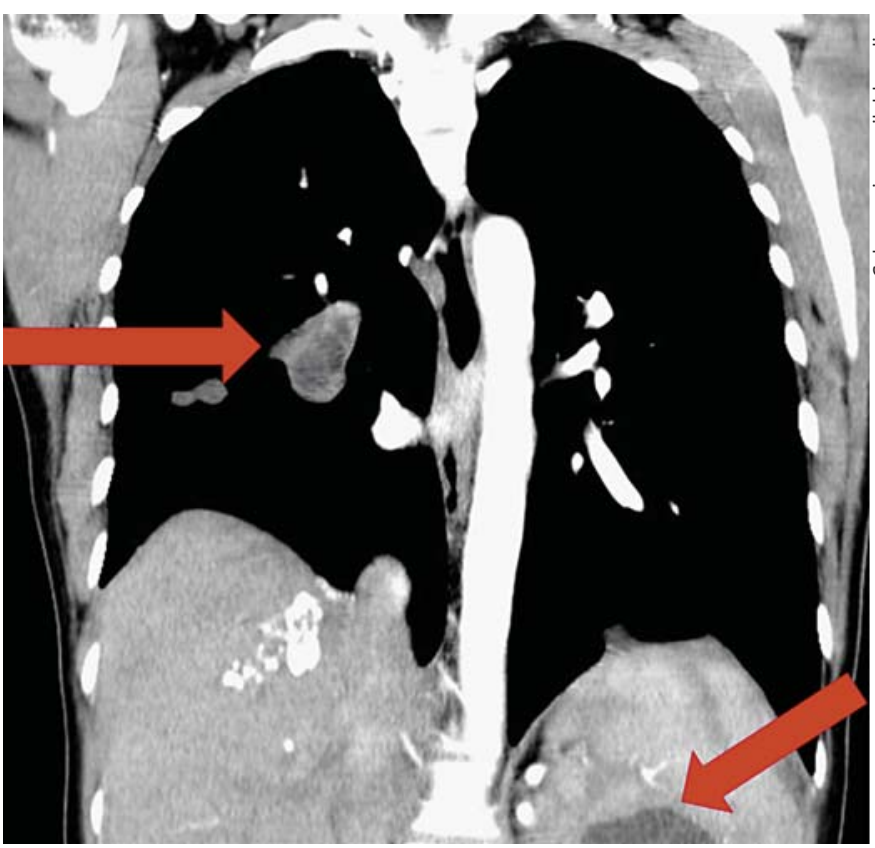

Fig. 2. Follow-up CT angiography. Coronal view showing PA obstruction indicative of echinococcal cysts localization. Abdominal echinococcal cysts with typical layers are shown (arrow).
Echinococcosis caused by Echinococcus granulosus, also known as hydatidosis or hydatid cysts, is a parasitic disease known from the time of Hippocrates [1]. Echinococcosis is prevalent in regions of Eurasia, several South American countries, North and Central America, and Africa. In the Western world, it is predominantly seen as an imported disease in immigrants from endemic countries $[2,3]$. Echinococcosis cysts grow slowly $(1-30 \mathrm{~mm}$ in diameter yearly) and about $80 \%$ occur in a single organ. Moreover, echinococcosis may involve any organ including the lungs, but cysts in the pulmonary artery (PA) are very rare $[1,4]$.

\section{Case Report}

A 44-year-old woman with a history of pulmonary embolism, left-sided nephrectomy, and abdominal echinococcosis complained of sudden thoracic pain and shortness of breath. She discontinued anticoagulation 7 years before presentation. Physical examination revealed a normal blood pressure and a saturation of $99 \%$. Due to

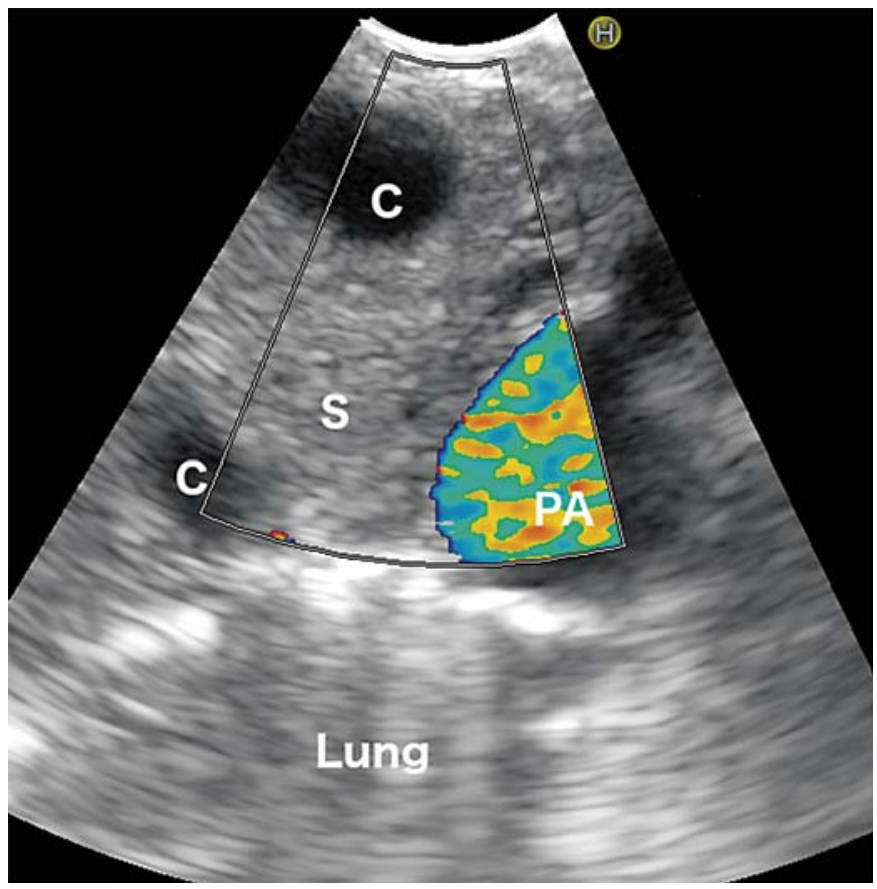

Fig. 3. EBUS image demonstrating intra-PA obstruction by echinococcal cysts surrounded by organized thrombus. The hypoechogenic aspect and absence of Doppler flow strongly support the cystic nature of the obstruction. The surrounded organized tissue is suspected for in situ thrombosis. $\mathrm{C}=$ Cyst. 
the sudden onset of symptoms and a history of pulmonary embolism, a D-dimer test was performed, which revealed a D-dimer of $77.5 \mathrm{mg} / \mathrm{l}$ (reference $\leq 0.5 \mathrm{mg} / \mathrm{l}$ ). She was initiated on low molecular weight heparin, and a CT angiography was performed under the suspicion of pulmonary embolism. The axial image on this CT angiography revealed a right lower and middle lobe PA obstruction (fig. 1). The diagnosis of recurrent pulmonary embolism was made and anticoagulation therapy was given. A follow-up CT angiography 3 months later showed persistent PA obstruction, and the presumed diagnosis of embolism was questioned as PA cysts seemed to be present (fig. 2). Importantly, these lesions on the coronal image resemble cysts compatible with echinococcosis. Endobronchial ultrasound (EBUS) that can be used to detect centrally located pulmonary emboli [5-7] demonstrated an inhomogeneous intravascular lesion containing multiple sharply demarcated round hypoechoic areas. In absence of Doppler flow, these lesions are compatible with the diagnosis of cysts (fig. 3). The combination of clinical presentation, follow-up CT angiography, and EBUS imaging made us reject the initial diagnosis of pulmonary embolism and support the diagnosis of PA echinococcosis. No signs of pulmonary hypertension on transthoracic echocardiography were present. In our patient, a prolonged (4 years up to now) treatment with albendazole has been chosen, as radical surgical treatment may lead to serious complications in this stage and is noncurative due to widely disseminated disease. The patient has remained stable for more than 4 years. In case of disease progression, including progressive PA obstruction with the risk of pulmonary hypertension or life-threatening hemoptysis, surgical resection will be considered.

\section{Discussion}

Although a minority of echinococcosis cases involves multiple sites, and cysts in the PA are very rare, this case demonstrates that echinococcosis may cause severe PA obstruction with a presentation of sudden thoracic pain and shortness of breath. In case of uncertainty of the diagnosis at noninvasive imaging, subsequent minimally invasive EBUS is an excellent diagnostic technique to visualize intra-PA cysts and differentiate them from pulmonary embolism. Due to the completely different therapeutic consequences, we decided that we needed more assurance of the diagnosis.

Morbidity in echinococcosis is usually secondary to spontaneous rupture of the cyst (with or without anaphylaxis), infection of the cyst, or dysfunction of the involved organ due to cyst growth. If located in the PA, pulmonary hypertension is a complication which has been described [8-10]. Mortality is secondary to anaphylaxis, systemic complications of the cysts (sepsis, respiratory failure) or perioperative complications. Surgical resection and percutaneous drainage are accepted treatments of echinococcosis cysts if located in the liver, spleen, or subcutaneously [1]. In case of PA, localization surgical resection of echinococcal cysts by arteriotomy with or without the need of pneumonectomy or pulmonary endarterectomy can be considered. Surgical treatment of PA echinococcosis has been reported but is considered high risk [1113]; therefore, this decision must be taken very carefully. To our knowledge, percutaneous drainage of the PA has not yet been performed.

\section{Financial Disclosure and Conflicts of Interest}

The authors have no conflicts of interest to disclose.

\section{References}

1 Fatimi SH, Schuuring MJ, Sheikh S: Rare relapsed extrapulmonary hydatid disease. J Coll Physicians Surg- Pak 2007;17:570-571.

-2 Vlaar APJ, Hovius JWR, Stijnis K, van Vugt M: Pareses, paralysis and parasites. Echinococcus granulosus infection. Neth J Med 2013; 71:529-533.

-3 Grosso G, Gruttadauria S, Biondi A, Marventano S, Mistretta A: Worldwide epidemiology of liver hydatidosis including the Mediterranean area. World J Gastroenterol 2012;18: 1425-1437.

4 David EP, Fernandez MAG, FernándezAvilés F: Isolated cardiac hydatidosis. Eur Heart J 2007;28:2829.

5 Aumiller J, Herth FJF, Krasnik M, Eberhardt R: Endobronchial ultrasound for detecting central pulmonary emboli: a pilot study. Respir Int Rev Thorac Dis 2009;77:298-302.

Endosonography of a PA Obstruction in Echinococcosis
6 Al-Saffar F, Ibrahim S, Seeram V, Bajwa AA, Shujaat A: Use of endobronchial ultrasound to evaluate nonthrombotic endovascular lesions in pulmonary arteries: a systematic review. J Bronchol Interv Pulmonol 2015;22: 28-32.

7 Dhillon SS, Harris K: Endobronchial ultrasound for the detection of chronic pulmonary artery thrombus. Endosc Ultrasound 2016;5: 272-273.

$\checkmark 8$ Bulman W, Coyle CM, Brentjens TE, Horn EM, Dickstein ML, Wilt JS, et al.: Severe pulmonary hypertension due to chronic echinococcal pulmonary emboli treated with targeted pulmonary vascular therapy and hepatic resection. Chest 2007;132:1356-1358.

9 Camporrotondo M, Vrancic M, Piccinini F, Navia D: Surgical treatment of pulmonary hypertension caused by echinococcosis disease. J Thorac Cardiovasc Surg 2014;147:e15-e16.
0 Buz S, Knosalla C, Mulahasanovic S, Meyer R, Hetzer R: Severe chronic pulmonary hypertension caused by pulmonary embolism of hydatid cysts. Ann Thorac Surg 2007;84: 2108-2110.

11 Kiral H, Evman S, Tezel C, Alpay L, Lacin T, Baysungur V, et al: Pulmonary resection in the treatment of life-threatening hemoptysis. Ann Thorac Cardiovasc Surg 2015;21:125131.

12 Koksal C, Baysungur V, Okur E, Sarikaya S, Halezeroglu S, Halezaroglu S: A two-stage approach to a patient with hydatid cysts inside the right pulmonary artery and multiple right lung involvement. Ann Thorac Cardiovasc Surg 2006;12:349-351.

13 Findikcioglu A, Kilic D, Canpolat T, Hatipoglu A: Necessity of lung resection in neglected cases of pulmonary hydatidosis. Ann Thorac Cardiovasc Surg 2010;16:187-189. 